\title{
Experimental Performance Studies on the Improved Expansive Subgrade Soil Formation by Using Mechanical Stabilization with Natural Gravel Around Jimma Quarry Sites
}

\author{
Anteneh Geremew, Basha Fayissa \\ Faculty of Civil and Environmental Engineering, Jimma University, Institute of Technology, Jimma, Ethiopia \\ Email address: \\ antjiren $a$ gmail.com (A. Geremew), bashafayisa $a$ gmail.com (B. Fayissa) \\ To cite this article: \\ Anteneh Geremew, Basha Fayissa. Experimental Performance Studies on the Improved Expansive Subgrade Soil Formation by Using \\ Mechanical Stabilization with Natural Gravel Around Jimma Quarry Sites. American Journal of Civil Engineering. \\ Vol. 6, No. 5, 2018, pp. 154-161. doi: 10.11648/j.ajce.20180605.13
}

Received: September 22, 2018; Accepted: November 2, 2018; Published: November 28, 2018

\begin{abstract}
Expansive soil refers to a particular type of soils - almost clayey soils in property - that expand as they absorb water and shrink when they dry out. The process of swelling generates pressures that can cause lifting, or heaving of structures whilst shrinkage process can cause differential settlement on civil structure. A large number of buildings and roads are placed on such type of soil and exposed to the danger from this swelling and shrinkage processes. In order to avoid the previous mentioned risk from the expansive soil, a technique of soil stabilization should be made for this type of soil to enhance some of its properties. In this study, the experimental investigations have been made to study the suitability of natural gravel from jiren quarry site to improve properties of expansive soil. The important parameters to be determine the geo-technical properties such as Specific gravity, Liquid limit, Plastic limit, Plasticity index, dry density and California Bearing (CBR) ratio values. According to ERA 2002 this type of soils is poor for subgrade for road construction. In order to realize the desired objective, a purposive sampling technique which is non -probability method was adopted in order to collect disturbed soil samples at depth of $1.5 \mathrm{~m}$ and natural gravel from jiren quarry site used for the preparation of different laboratory tests. The laboratory work involved sieve analysis along with consistence test to classify the soil sample. The preliminary investigation of the soil shows that it belongs to A-7-5 class of soil in AASHTO and CH in USCS soil classification system. Soils under this class are generally of poor for subgrade road construction. Atterberg limits, compaction and CBR tests were used to evaluate properties of stabilized soil. The soil was stabilized with natural gravel in stepped concentration of $5 \%, 10 \%, 15 \%, 20 \%$ and $25 \%$ by dry weight of the soil. Analysis of the results shows the addition of natural gravel improve the geotechnical properties of the expansive black cotton soil. The addition of natural gravel reduces plasticity index, swelling and OMC with an increase in MDD and CBR with all increased natural gravel contents. The addition of $20 \%$ and $25 \%$ of natural gravel established an increased CBR value by $670 \%$ and $958 \%$ respectively, indicating the subgrade class falling under S4 and S5 respectively. From this study it was found out that natural gravel stabilized with soil do meet the minimum requirement of ERA pavement manual specification for use as a sub-grade material in road construction.
\end{abstract}

Keywords: Expansive Soil, Stabilization, Swelling, Shrinkage, Natural Gravel, Subgrade, CBR Vale

\section{Introduction}

Ethiopia one of fasts growing country in East Africa has been scoring two digit economic growth rates for the past years. There are different types of abundant natural resource distribution in the country; the accessibility of untouched surface and subsurface material it makes the country the second famous in Africa further it makes the nation and nationality to be beneficial with this resources. One of the popular sectors for development was the construction; it increases participation of population during operation that makes beneficial for the society and 
changes there living standards. Know a day the economic back ground of the country was gradually shifted from agricultural-economy to industrial, which needs shifting agricultural labors to that of the industrial workers, that makes them beneficially from their country as a nation. Ethiopian government gives more attention on constructs different industrial parks across the country that gives more opportunity those graduate and increase the utilization natural resources of the country. Therefore the construction of industries plays a great role for the development of the country and also the nation [1].

Road transport was one of typical modes of transportation especially in Ethiopia. In order to transport the raw material from the source or area of cultivated to industry parks, to distribute the product to different customers and for passenger it requires comfortable a road segments. The distribution of expansive soil in Ethiopia covers about $40 \%$ of the total surface area of the country [2]. Therefore most of the road constructed in expansive soil shows different types of distress and this leads to fail before there design period due to the swelling the shrinkage properties of expansiveness of the soil [3]. Thus, the selection process of route corridor influence the pavement structure and the construction costs, a thorough investigation should be done on the characteristics of subgrade soil [4].

According to the report of addis ababa city road authority in 2004 the annual allocation for road construction and maintenance about 300 million Ethiopian birr; out of this 30 million Ethiopian birr was allocated for routine maintenance which was obviously huge budget and it needs special attention on the subgrade soil, construction material and design of the projects.

Currently costs relating to transporting the construction materials for quarry site to road project to be considerable impact upon the overall initial cost road construction. Hence material search is generally restricted to about $10 \mathrm{~km}$ corridor centering on the road [5].

One of the typical approaches of improving weak subgrade soil such as expansive subgrade soil is removing and replacing with high strength subgrade material in order to resist load coming from surface of pavement, so the cost replacing of weak subgrade soil has caused highway agencies to assess alternative methods to construct the highway over weak subgrade. As a result, soil stabilization is one of the most suitable alternatives which are widely used in pavement construction; specifically mechanical stabilization for developing country [6].

Its observed that expansive soil overcomes an appreciable part of Ethiopia and most of the studies have been done on behavior, characteristics and engineering properties. Control and Mitigation of the swell-shrink behavior of expansive soil can be accomplished in several ways [12]

Therefore in order to reduce the initial road project constructed on expansive soil treating by mechanical stabilizing the soil with natural gravel obtain from quarry site for the preparation of subgrade soil in order to minimize the initial cost of the project.

\subsection{Statement of the Problem}

The swell and shrinkage distinctiveness of expansive soil causes significant damage to structures such as buildings and pavements. The above problems are extensively occurring in Ethiopia. The aerial coverage of expansive soils in Ethiopia is estimated to be 24.7 million acres [7].

One of the typical approach of improving weak subgrade soil such as expansive subgrade soil is removing and replacing with high strength subgrade material in order to resist load coming from surface of pavement, so the cost replacing of weak subgrade soil has caused highway agencies to assess alternative methods to construct the highway over weak Subgrade. As a result, soil stabilization is one of the most suitable alternatives which are widely used in pavement construction; specifically, mechanical stabilization [6]. Since most soil which is found in Jimma zones have high plastic index and low CBR value; this property of this expansive soil has low resistance to axial load applied on the surface of the pavement makes it deteriorated. Therefore, the movement of the sub-grade is one of the causes of road pavement deterioration. Therefore due to the above problems the researcher looking the mechanism to improve the bearing capacity of the subgrade soil by means of mechanical stabilization the soil by natural gravel material around jimma town in order to reduce the swelling and shrinkage properties.

The main objective of the study assess the performance on the improved expansive subgrade soil formation by using Mechanical stabilization of natural gravel around Jimma Quarry sites for roads construction with the following specific objective such as: to identify engineering properties of natural gravel around Jimma quarry site, to determine mix proportion of the natural gravel material from different quarry sites to improve the engineering properties of the mix , to identify the engineering properties of optimum stabilized natural gravel with expansive subgrade soils for road construction in different percentage mixture and To compare the laboratory results with ERA standard specification.

\subsection{Significance of the Study}

(1) In order to reduce transporting cost of material from quarry site to road project.

(2) It minimize initial cost of project when stabilized with natural gravel when compare to other method of stabilization technics and to avoid removing of expansive soil on the embankment.

(3) It encourage the use of locally available material for road construction having low plasticity index and higher CBR vale for effective utilization of material without wasting the original material.

(4) In order to avoid delays of raw materials supplying industrial park at the required time.

\subsection{Scope of the Study}

The scope of the study is limited to establishing a proper mix (blending) for the natural gravel from Jiren quarry site 
with poor expansive subgrade soil in order to obtain low Plasticity index and high value of CBR.

The study area covers only expansive soils and Natural gravel from Jiren quarry site. The collected soil samples was disturbed and taken from $1.5 \mathrm{~m}$ depth in order to avoid organic material. This would be achieved through Experimental laboratory tests by trial and error method.

\section{Methodology}

\subsection{Study Design}

Experimental study designs were used in this study. It was attempted to conducted laboratory tests such as sieve analysis, Atterberg limits, Specific gravity, CBR value, and Standard Proctor compaction tests on natural soil samples treated with different proportion of natural gravel and checking to standard specification.

The stages involved in the study include-

(1) Taking sample

(2) Preparation of sample for each laboratory tests

(3) Conducting laboratory tests Sieve analysis, specific gravity, Atterberg limit, Compaction, and CBR for natural expansive soil.

(4) Process of mixing natural gravel with soil in different amount.

(5) Conducting laboratory tests Atterberg limit, Compaction, and CBR for blended expansive soil.

(6) To find out effect of additive at different percentage that satisfies requirement of the standard specification.

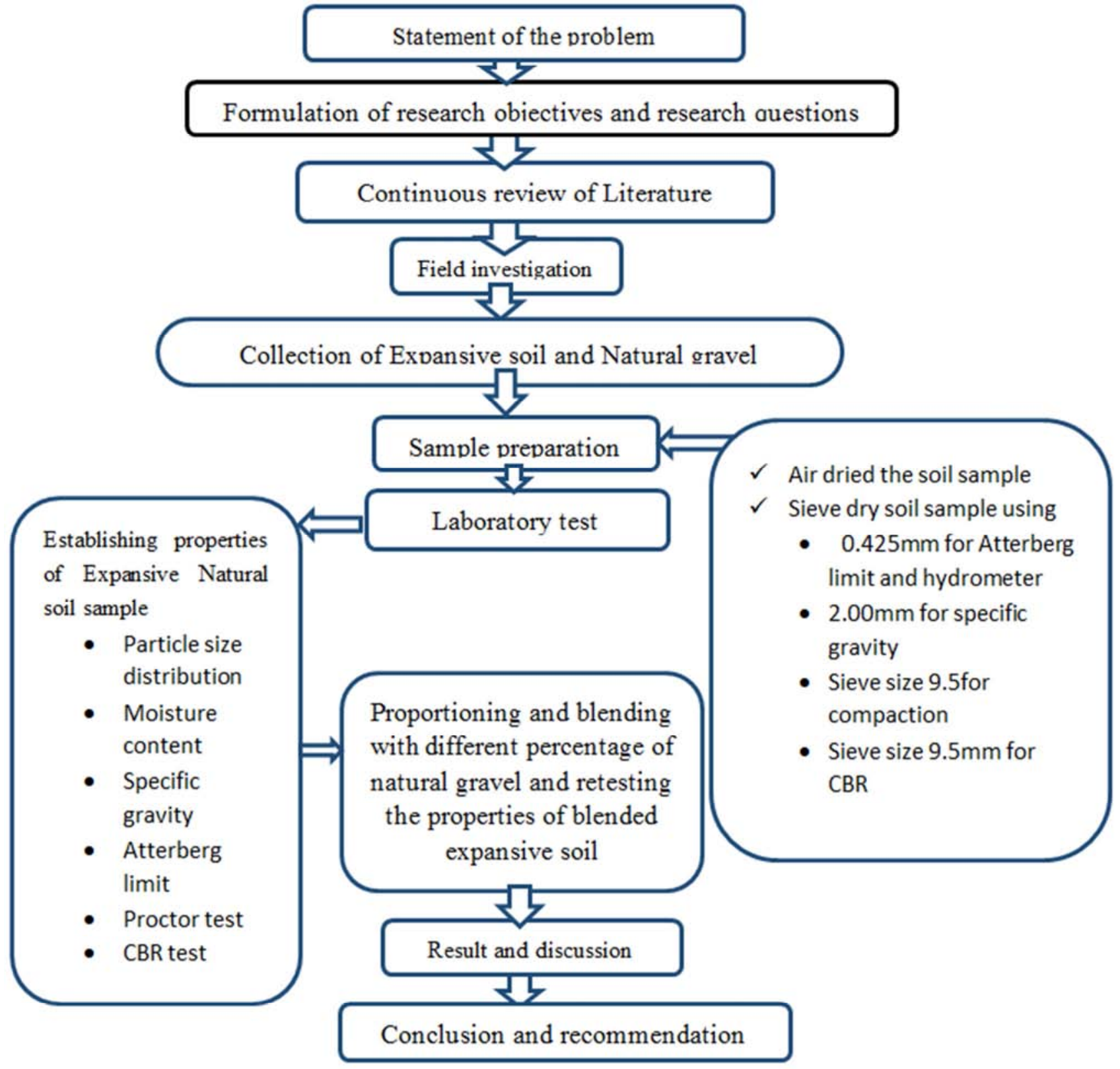

Figure 1. Research Design Chart. 


\subsection{Sampling Procedure}

Sampling procedures for natural gravel was Purposive-sampling techniques and quartering sampling techniques is used for sample preparation. After retrieving samples, laboratory testing was undertaken to assess the material suitability. Initially material classification tests such as grain size analysis, liquid limit, plastic limit, plasticity Index was undertake, followed by assessment of strength parameters such as compaction, and California bearing ratio. All the tests had been performed in accordance to AASHTO Standards.

\subsection{Study Variables}

The study variables are categorized into two. These are dependent variable and independent variables.

Dependent variable

Effect of natural gravel on expansive subgrade soil Independent Variables

(1) Dosage of natural gravel.

(2) Plastic limit, liquid limit, MDD, OMC and CBR of unblended and blended expansive soil.

\subsection{Data Collection Process}

During data collection, data were collected from primary and secondary source. Primary data where obtained by laboratory tests result and secondary data's are literature and materials used for this research from different source.

\subsection{Field Identification}

Reconnaissance survey was done to establish representative sample locations of soils. The soil sample locations are selected using visual inspections and applying experience and engineering judgments and purposively at least 3(three) disturbed representative expansive soils will be collected at depth of $1.5 \mathrm{~m}$; from this samples high plastic limit and low CBR value was taken for study the properties of expansive soil. Finally the natural gravel was collected from jiren quarry site for the analysis of the study.

\subsection{Sample Preparation}

Before treating and testing, the sample was prepared in accordance with the described AASHTTO T87-86. This method includes:

(1) Air and oven dried the samples.

(2) Preparing uniform samples for Atterberg Limits tests. And the other for Compaction and Californian bearing ratio tests.

(3) Mixing soil and natural gravel manually to get uniform mix for each test.

\subsection{Methods and Standard Testing Procedure}

Standards and specifications for this study were adapted from AASHTO, ASTM and IS.
Table 1. Standards and Specification for this Study.

\begin{tabular}{lllll}
\hline \multirow{2}{*}{ No. } & Laboratory tests & Standards & & \\
\cline { 3 - 4 } & & AASHTO & ASTM & IS \\
\hline 1 & Moisture Content & T265 & & \\
2 & Grain Size Analysis & & D422-63 & \\
3 & Atterberg Limits & & D4318-98 & \\
4 & Soil Classification & & D2487-98 & \\
5 & Specific Gravity & D854-83 & \\
6 & Standard Proctor Compaction & & D698-98 & \\
7 & CBR & T193-93 & & \\
\hline
\end{tabular}

\section{Result and Discussion}

\subsection{Engineering Properties of Natural Gravel from Jiren Quarry Site and Untreated Expansive Soil}

Table 2. Geotechnical properties of Natural Gravel from Jiren quarry site was summarizes in table sown below.

\begin{tabular}{lll}
\hline S/N & Property & Observed Values \\
\hline 1 & Classification & \\
& AASHTO (group index) & A-2-7 \\
& USCS group symbol & $\mathrm{GW}$ \\
& USCS group name & Well-graded gravels \\
2 & Specific gravity & 2.74 \\
3 & Particle size analysis & \\
& Gravel content\% (20 to $4.75 \mathrm{~mm})$. & 23.65 \\
& Sand content \% (4.75 to 0.075mm) & 21.35 \\
& Silt and clay content \% (below 0.075mm.) & 5.05 \\
& Atterberg's Limits: \% & 60.28 \\
& Liquid limit & 45.03 \\
& Plastic limit & 15.26 \\
& Plasticity index & \\
5 & Proctor test & 21.2 \\
& Optimum moisture content (OMC), \% & 1.44 \\
& Maximum dry density ( g/cm3) & 28.16 \\
\hline
\end{tabular}

Table 3. Geotechnical properties of untreated expansive soil were summarizes in table sown below.

\begin{tabular}{|c|c|c|}
\hline $\mathbf{S} / \mathbf{N}$ & Property & Observed Values \\
\hline \multirow{4}{*}{1} & Classification & \\
\hline & AASHTO (group index) & A-7-5 \\
\hline & USCS group symbol & $\mathrm{CH}$ \\
\hline & USCS group name & Highly Plastic Clay \\
\hline 2 & Specific gravity & 2.6 \\
\hline \multirow{4}{*}{3} & Particle size analysis & \\
\hline & Gravel content $\%$ ( 20 to $4.75 \mathrm{~mm}$.) & 0.588 \\
\hline & Sand content $\%$ (4.75 to $0.075 \mathrm{~mm})$ & 5.514 \\
\hline & Silt and clay content $\%$ (below $0.075 \mathrm{~mm}$.) & 93.898 \\
\hline \multirow{4}{*}{4} & Atterberg's Limits: \% & \\
\hline & Liquid limit & 88.65 \\
\hline & Plastic limit & 32.37 \\
\hline & Plasticity index & 56.28 \\
\hline \multirow{3}{*}{5} & Proctor test & \\
\hline & Optimum moisture content (OMC), $\%$ & 35.8 \\
\hline & Maximum dry density ( g/cm3) & 1.26 \\
\hline 6 & California Bearing Ratio value \% (Soaked) & 1.5 \\
\hline
\end{tabular}




\subsection{Engineering Properties of Treated Expansive Soil}

\subsubsection{The Effect of Natural Gravel on Atterberg Limit}

Table 4. The Effect of Different percentage of Natural gravel on Atterberg limit.

\begin{tabular}{|c|c|c|c|c|}
\hline Additive Content & Liquid Limit, \% & Plastic Limit, \% & Plastic Index, \% & Swelling Potential \\
\hline Expansive Soil & 88.65 & 32.37 & 56.28 & High \\
\hline Expansive soil+5\% Natural Gravel & 79.12 & 29.25 & 49.87 & High \\
\hline Expansive soil+10\% Natural Gravel & 62.64 & 21.11 & 41.53 & High \\
\hline Expansive soil+15\% Natural Gravel & 48.21 & 19.63 & 28.58 & Medium \\
\hline Expansive soil $+20 \%$ Natural Gravel & 37.60 & 12.23 & 25.37 & Medium \\
\hline Expansive soil $+25 \%$ Natural Gravel & 26.19 & 10.89 & 15.30 & Medium \\
\hline
\end{tabular}

From Table 4 plastic index has improved through the addition of different proportion of Natural gravel and untreated expansive soil plasticity index values determined in laboratory were $56.28 \%$.

The addition of $5 \%, 10 \%, 15 \%, 20 \%$, and $25 \%$ Natural gravel improved the untreated expansive soil plasticity index by $11.29 . \%, 26.21 \%, 49.22 \%, 54.92 \%$ and $72.8 \%$ respectively.

\subsubsection{The Effect of Natural Gravel on Maximum Dry Density}

The Standard Proctores ${ }^{\text {ee }}$ test for soil with natural gravel mixes are performed and presented in Table 5 and Figure 2 The values for the maximum dry densities were noted to significantly increase with the addition of natural gravel from a neat value of $1.26 \mathrm{~g} / \mathrm{cm} 3$ to a maximum value of $1.37 \mathrm{~g} / \mathrm{cm} 3$ attained in the blend $25 \%$ natural gravel. Thus the materials used to improve the gravels were found to facilitate the closer packing of the gravel particles and thus an increase in the maximum dry density. The $\mathrm{OMC}$ was found to decrease from $35.8 \%$ to $26.88 \%$ this may be attributed to the addition of natural gravel as stabilizer.

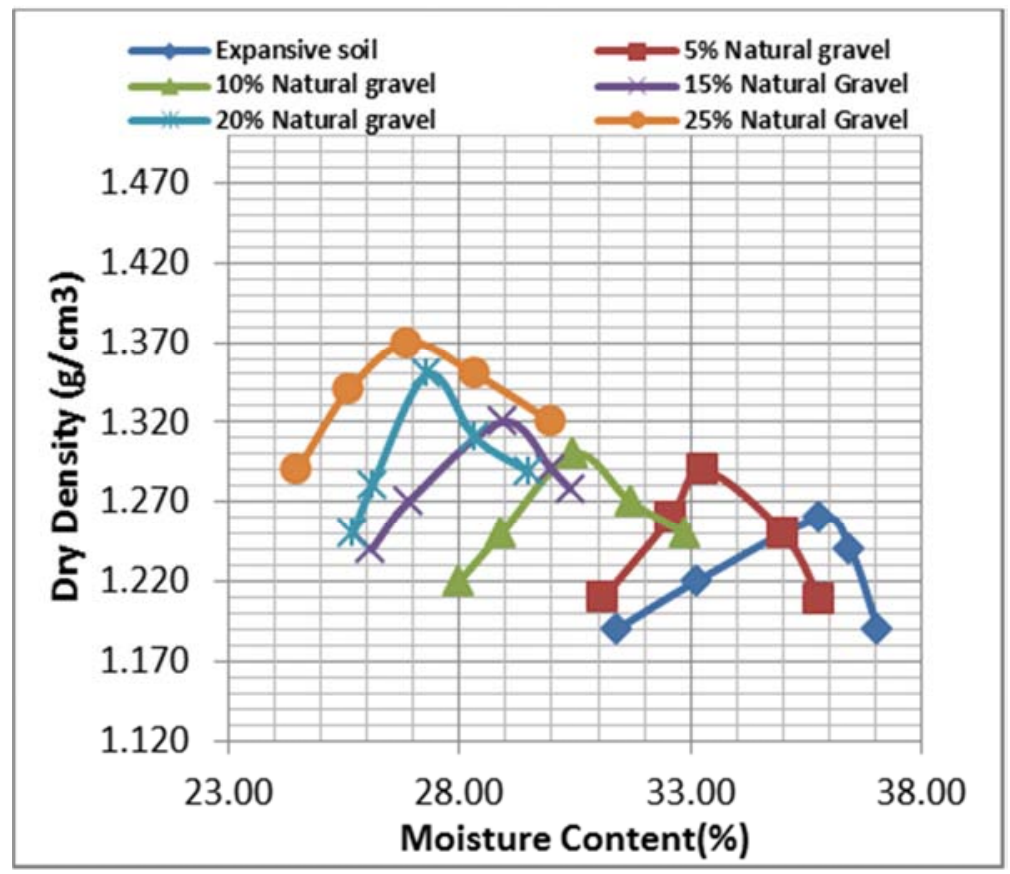

Figure 2. Effect of different percentage of Natural gravel on compaction.

Table 5. The Effect of Different percentage of Natural gravel on Maximum dry density.

\begin{tabular}{lll}
\hline Additive Content & OMC (\%) & MDD $\left(\mathbf{g} / \mathbf{c m}^{\mathbf{3}}\right)$ \\
\hline Expansive soil & 35.8 & 1.26 \\
Expansive soil+5\% Natural Gravel & 33.28 & 1.29 \\
Expansive soil+10\% Natural Gravel & 30.47 & 1.3 \\
Expansive soil+15\% Natural Gravel & 28.92 & 1.32 \\
Expansive soil+20\% Natural Gravel & 27.31 & 1.35 \\
Expansive soil+25\% Natural Gravel & 26.88 & 1.37 \\
\hline
\end{tabular}

The effect of natural gravel on the optimum moisture content for the soil is shown in figure 3. The optimum moisture content for different percentage of natural gravel decreased as the percentage of natural gravel increase from $4.3 \%$ to $17.09 \%$. The OMC for the natural soil is 35.8 , in the process of stabilizing the expansive black cotton soil the addition of $5 \%, 10 \%, 15 \%, 20 \%$ and $25 \%$ natural gravel decreased the OMC as 33.28, 30.47, 28.92, 27.31 and 26.88 respectively. 


\section{$\%$ Natural Gravel Vs MDD (g/cm3)}

\section{4}

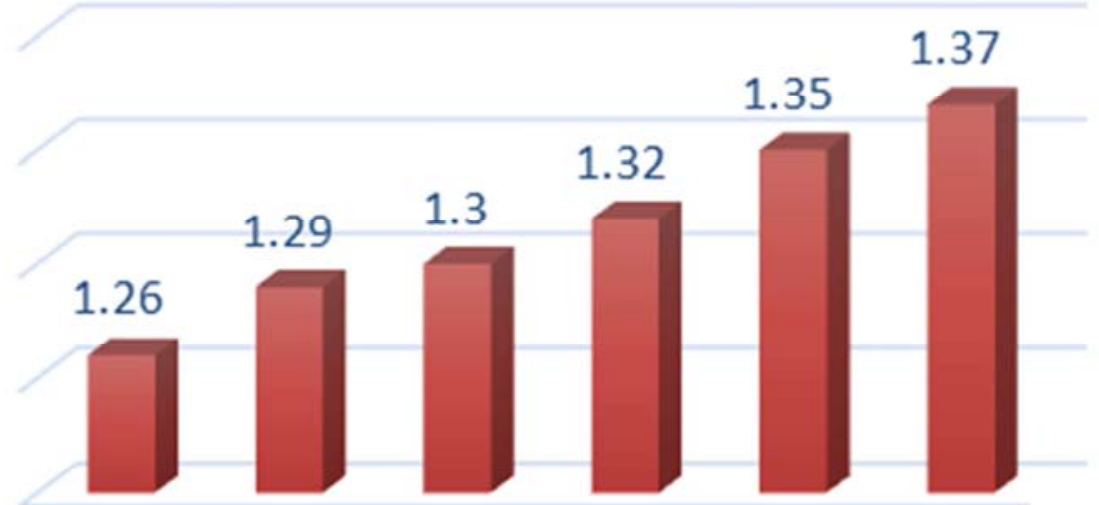

1.2

$\begin{array}{cccccc}\text { Expansive } & \text { Expansive } & \text { Expansive } & \text { Expansive } & \text { Expansive } & \text { Expansive } \\ \text { soil } & \text { soil }+5 \% & \text { soil }+10 \% & \text { soil }+15 \% & \text { soil }+20 \% & \text { soil }+25 \% \\ & \text { Natural } & \text { Natural } & \text { Natural } & \text { Natural } & \text { Natural } \\ & \text { Gravel } & \text { Gravel } & \text { Gravel } & \text { Gravel } & \text { Gravel }\end{array}$

Figure 3. Effect of different percentage of Gravel on MDD.

\section{$\%$ Natural Gravel Vs moisture contenet (\%)}

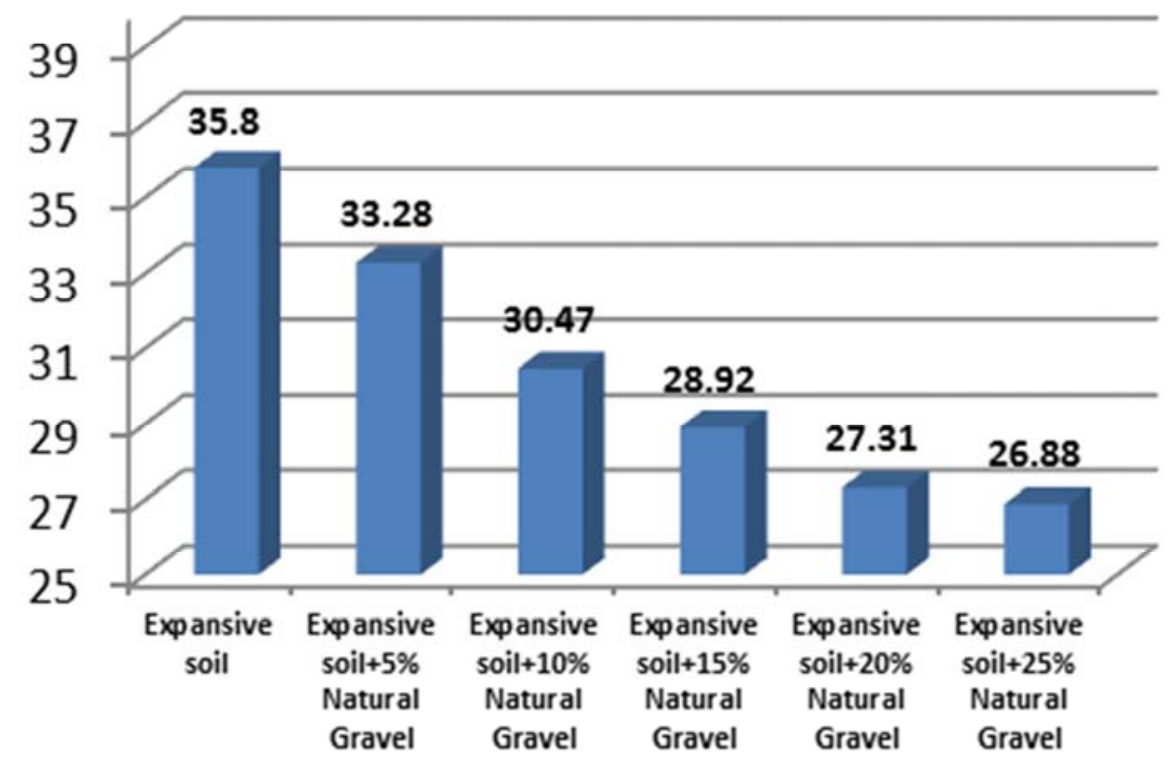

Figure 4. Effect of different percentage of Gravel on moisture content.

The effect of natural gravel on the optimum moisture content for the soil is shown in figure 4. The optimum moisture content for different percentage of natural gravel decreased as the percentage of natural gravel increase from $4.3 \%$ to $17.09 \%$. The OMC for the natural soil is 35.8 , in the process of stabilizing the expansive black cotton soil the addition of $5 \%, 10 \%, 15 \%, 20 \%$ and $25 \%$ natural gravel decreased the OMC as 33.28, 30.47, 28.92, 27.31 and 26.88 respectively. 


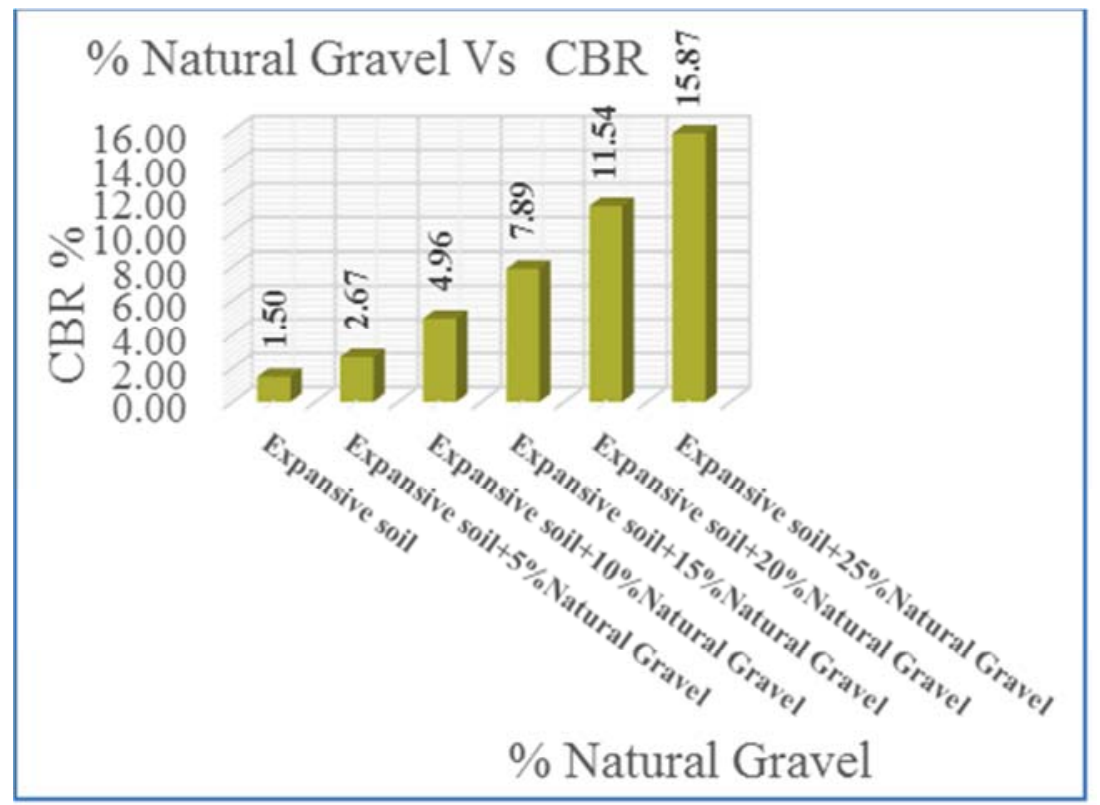

Figure 5. Effect of different percentage of Gravel on CBR value.

The CBR for the natural soil was $1.5 \%$, indicating very poor quality. The addition of $5 \%, 10 \%, 15 \%, 20 \%$ to $25 \%$ natural gravel increased the CBR by $78 \%, 230 \%, 426 \%, 670 \%$ and $958 \%$ respectively. This shows that the strength of the black cotton soil increased with an increase of percentage of natural gravel.

Table 6. Subgrade class of soil with natural gravel.

\begin{tabular}{ll}
\hline Additive Content & Subgrade Class \\
\hline Natural Soil & S1 \\
Natural Soil $+5 \%$ Natural gravel & S2 \\
Natural Soil $+10 \%$ Natural gravel & S3 \\
Natural Soil $+15 \%$ Natural gravel & S4 \\
Natural Soil $+20 \%$ Natural gravel & S4 \\
Natural Soil $+25 \%$ Natural gravel & S5 \\
\hline
\end{tabular}

According to ERA 2002 site investigation manual, a material with $\mathrm{CBR}$ value less than $2 \%$ are very difficult to work and subgrade would lead to uneconomical pavement structure, its recommended to cover with selected material or treating it with other stabilizing material. Therefore, the soil requires initial modification and/or stabilization to improve its workability and engineering property. Therefore, the addition of $20 \%$ and $25 \%$ of natural gravel modifies the soil to a suitable subgrade material for pavement construction. The swell value of the natural soil decreased with an increase of natural gravel, as indicated on figure 6 .

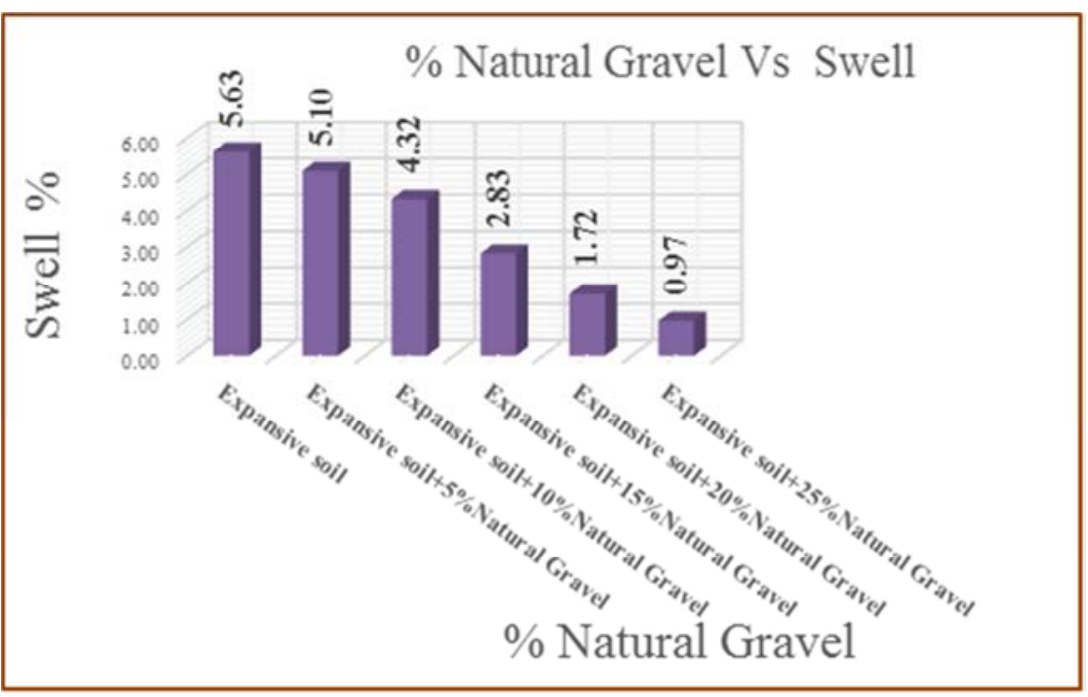

Figure 6. Effect of different percentage of Gravel on Swell.

The swell value for different percentage of natural gravel decreased as the percentage of natural gravel increased. The swell value for Natural gravel of 5\%, 10\%, 15\%, 20\% and 25\% increased by $9.41 \%, 23.27 \%, 49.73 \%, 69.5 \%$ and $82.77 \%$ respectively. A decrease in swelling potential due to anticipated moisture indicates the soil resistance for volume instability decreases. 


\section{Result Summery}

The natural expansive soil exhibits an engineering property of specific gravity having a value of 2.6, soil classification of A-7-5 according to ASSTHO, a plastic index of 56.28 and a low CBR value of 1.5 which indicates the soil to be poor for engineering use. Therefore, it needs modification. The addition of natural gravel modified the engineering property of the soil to a suitable material for subgrade construction. The effect of the addition of a stepped value of $5 \%, 10 \%, 15 \%, 20 \%$ and $25 \%$ natural gravel modified the value of the engineering properties investigated in this research. The plastic index decreased from $11.39 \%$ to $72.8 \%$, the MDD increased from $4.41 \%$ to $17.09 \%$ while OMC decreased from $33.28 \%$ to $26.88 \%$, and the CBR value increased from $78 \%$ to $950 \%$ while the swell decreased by $9.41 \%$ to $82.77 \%$. According to ERA manual, the addition of $20 \%$ and $25 \%$ of natural gravel changed the subgrade class of the natural soil from S3 to S5. which makes the natural soil suitable material to be utilized as subgrade construction material.

\section{Conclusion}

On the basis of the results obtained in the experimental investigation, the following conclusions have been drawn.

(1) The natural subgrade soil of the subject area was generally classified as a material of poor engineering property to be used as a sub-grade material, it requires initial modification and/or stabilization to improve its workability and engineering property.

(2) The addition of natural gravel in natural expansive soil, the value of liquid limit and plastic limit increased until $20 \%$ of natural gravel and decreased after $20 \%$ natural gravel, leading the plasticity index of stabilized natural expansive soil to reduce.

(3) The values for the maximum dry densities were noted to significantly increase with the addition of natural gravel and the OMC was found to decrease.

(4) According to ERA 2002 site investigation manual, a material with CBR value less than $2 \%$ are very difficult to work and subgrade would lead to uneconomical pavement structure, its recommended to cover with selected material or treating it with other stabilizing material. The natural soil has CBR value of $1.5 \%$. Therefore, the soil requires initial modification and/or stabilization to improve its workability and engineering property.

(5) The addition of $20 \%$ and $25 \%$ of natural gravel modifies the soil to a suitable subgrade material for pavement construction increasing the value of CBR by $670 \%$ and $958 \%$. The subgrade class of the stabilized soil by $20 \%$ and $25 \%$ falls under the class of S4 and S4 respectively.

Generally, natural soil and treated expansive soil properties were computed based from laboratory test results. Each observed values were presented according to the requirements of ERA standard specifications. Based on the laboratory result the natural soil did not satisfy the requirements of ERA standard specifications for subgrade construction. However, after blending with $20 \%$ and $25 \%$ natural gravel, the mix proportion satisfied ERA standard specifications for subgrade construction.

\section{Recommendation}

(1) Further studies in the addition of natural gravel should be carried out in order to find out the effect that natural gravel has on different types of soils and under different exposure conditions.

(2) Further studies should be carried out in order to identify the long term effects that natural gravel has on the durability of the road pavement structures.

(3) Encourage the use of locally available material for road construction having low plasticity index and higher CBR vale.

\section{References}

[1] Abebe WoldeGiorgis, 2017. Ethiopia: The Construction Industry in Bolstering Growth. www.allafrica.com , 23 February 2017.

[2] Fekerte Arega, Freek van der Meer and Harald van der Werff, 2009, Prediction of Volumetric Shrinkage in Expansive Soils (Role of Remote Sensing), Intechopen.com, Advances in Geoscience and Remote Sensing.

[3] Tekeste Gebrehiwot, 2003, Ameliorated Design and Construction Techniques of Pavements on Expansive Soils, MSc Thesis, Addis Ababa University, Ethiopia.

[4] John R. Wise W. and Ronald Hudson, July 1971. An examination of expansive clay problems in texas. Research Report Number 118-5.

[5] Ethiopian Roads Authority. (2011) "Site investigation manual".

[6] Catherine May Caunce, 2010. Effective Road Pavement Design for Expansive Soils in Ipswich. Research Project.

[7] Fiker Alebachew, 2005, Pavement Distresses on Addis Ababa City Arterial Roads, Causes and Maintenance Options, MSc Thesis, Addis Ababa University, Ethiopia.

[8] Ethiopian Roads Authority, 2013, Pavement Design manual, Addis Ababa, Ethiopia.

[9] American society for testing and materials (1991). Annual Book of ASTM Standards, Vol. 04.08. Philadelphia, Pa.

[10] Braja M. Das, 2002 SOIL MECHANICS LABORATORY MANUAL Sixth Edition.

[11] Muni Budhu, 2005. Soil Mechanics fundamentals, USA.

[12] Bantayehu Uba Uge , 2017, International Journal of Scientific Research Engineering \& Technology. 